\title{
Measures to Improve the Economic Benefits of Agriculture and Agricultural Products in China
}

\author{
Bin Huang, Qing Wang \\ Nanchang Uinversity College of Science and Technology, Nanchang, 330026 \\ Jiangxi Technical College of Manufacturing, Nanchang, 330095
}

Keywords: agriculture, economic benefits of agricultural products, improvement measures

\begin{abstract}
China is a big country of agriculture, where agriculture occupies an important position in national economy. As an effective measure to stimulate the healthy development of agricultural economy of our country, it is also the main way to promote economic development, the prosperity of people as well as the income level of farmers by improving agricultural development level, agricultural competitiveness and economic benefits of agricultural products. By taking the current situation of agricultural development in China into consideration, in order to improve the economic benefits of agriculture and agricultural products, it is necessary to increase policy support, adjust agricultural structure, promote the automatic development of agricultural production mechanization and enhance the comprehensive quality of growers. This paper will make a detailed analysis of this problem.
\end{abstract}

\section{Introduction}

In recent years, the economy of agriculture and agricultural products in our country has been greatly improved, but there are also many problems in the process of development, such as the relative lack of agricultural resources, slow growth of farmers' income, and stagnation in some areas. All of these lead in that the gap of economic level of rural and urban areas gradually widen, farmers are unable to make a profit in agricultural production, a large number of rural young and young adults have been put into the ranks of urban migrant workers, the aging of the rural population is serious, and some agricultural production is completed only by the elderly, all of which bring extremely adverse effects on the development of agriculture and the economic promotion of agricultural products and hinders the development of agricultural development in China. China is a great country with the largest population the world. According to related statistics, the population of our country has reached 1.375 billion in 2015, accounting for about twenty percent of the world's population. Raising agricultural level in China has become the only way to solve the food problem. Moreover, with the development of our country's economy, people's material living standard has been greatly improved. Accordingly, the requirements for the safety and quality of agricultural products are becoming higher and higher. The quality improvement of agricultural products is also an effective way to improve the economic benefits of agricultural products, while improvement in the economic benefits of agricultural products can effectively drive the development of agriculture in our country. This virtuous cycle formed between agriculture and agricultural economy is propitious to effectively improve the agricultural development level in China.

\section{Reasons Why the Economic Benefits of Agriculture and Agricultural Products can Not be Effectively Improved in China}

The scarcity of agricultural resources is a great obstacle to China's agricultural development and it is not conducive to the long-term development of agriculture in our country. China's agricultural development depends greatly on agricultural resources. However, our per capita share of agricultural resources is obviously lower than the world average. In recent years, due to various 
factors, it is still decreasing gradually, which leads to the worrying prospect of agricultural development in China. In particular, the scarcity of land resources and water resources is extremely unfavorable to the development of agricultural economy. As the process of urbanization in China is accelerating, the increasing level of industrialization demands more and more occupation of land while the farmland of our country is continuously losing. Data shows that from 1998 to 2010, the area of farmland in China has been reduced by 7.97 million hectares. The main reasons for this problem lie in the development of real estate for land, expansion of urban areas, road construction and garden construction, etc. In some areas, there are problems such as low utilization rate of farmland, soil pollution and degradation of farmland led by land desertification. In addition, per capita share of water resources in China is relatively low, and farmland in some areas can not even be effectively irrigated, which make the development of agriculture in our country face great challenges.

Through careful reading of our country's related agricultural policies, it can be found that in most policies like the domestic control measures of grain trade, National Grain Reserve and acquisition measures, minimum price subsidies for agricultural products, and the grain pricing and purchasing etc, there is a will to favor industry and city. Government purchases agricultural products after adjusting price, which largely restricts the free development of agriculture and affects the improvement of agricultural productivity.

Due to the remaining influence of traditional farming mode and farmers' pressure of survival, in the past agricultural production, agricultural producers relied on the use of chemical pesticides and fertilizers to improve the production of agricultural products and prevent and control diseases and pests. With the development of science and technology, modern agriculture can increase crop yield by applying inorganic chemical fertilizers and use new technology and physical method of plant protection to prevent and control diseases and pests. However, some agricultural producers still use the traditional methods to engage in agricultural production, which leads to the continuously growing pollution and destruction of farmland. Besides, as more and more foreign varieties are entering Chinese agricultural market, in order to gain more economic benefits, farmers begin to grow large quantities of some kinds of crops, such as genetically modified agricultural products. Although there are advantages of high yield and good resistance to adversity, they will produce gene pollution and harm to farmland ecosystem as well as adverse impact on the development of local crops in China.

Low level of agricultural mechanization in China is also the main factor that affects the development of agricultural economy. Because most agricultural machinery and equipment in our country imitate the mechanical equipment of developed countries, the high cost price and farmers' insufficient economic ability hinder the popularization of agricultural machinery and equipment in production. Although some producers adopt agricultural machinery and equipment, they are in lack of professional knowledge support in the later maintenance. In particular, the number of after-sale points for maintenance of agricultural machinery and equipment is seriously inadequate in our country. Corresponding guarantee for the users can not be offered, which leads to the low popularization rate, lagging behind the developed countries greatly.

\section{Effective Measures to Improve the Economic Benefits of Agriculture and Agricultural Products in China}

Agricultural production is the process of making use of resources to create benefits. Only by making rational use of various resources, rationally allocating and making the best use of resources, can the economic growth of agriculture and agricultural products be promoted. Agriculture mainly involves natural resources and human resources. Due to different conditions in each region, the integrated allocation of resources should be combined with local characteristics, and the allocation scheme suitable for local application and promotion should be formulated. For example, the rational use of land resources requires the control of unreasonable real estate development in combination with local conditions. If some small cities do not have the need of urban expansion, it is vital to avoid unnecessary land use, control land resources rationally, and strictly punish irrational 
construction and irrational occupation of farmland. The rational utilization of water resources reflects in the following two aspects: the coordination of water resources between different regions and sewage treatment. For example, the south-to-north water diversion project is a large successful case of water resource allocation. In agricultural development, in regions where water resources are very scarce, it is suggested to find the nearest area with abundant water resources and make a scientific and reasonable allocation scheme of water resource, so as to ensure the basic water consumption of agricultural planting. Water pollution in China is relatively serious. In this regard, China has invested a lot of manpower and material resources in water pollution control. Especially in recent years, the general secretary of $\mathrm{Xi}$ has put forward the slogan of "Nature is the true treasure". All places have strengthened environmental protection work and proposed certain standards for agricultural water in which only clean water resources are suitable for farmland irrigation. Therefore, local places are required to unremittingly put environmental protection work into the key work contents and strengthen the control of water pollution. The rational use of human resources for agricultural production requires the continuous innovation of agricultural cultivation and management mode by the government and local authorities. By improving the economic benefits of agricultural products, publicizing deep achievements made in hometown agriculture, and making use of people's feelings on the rural areas, it is possible to make more people realize that agricultural cultivation can not only produce economic benefits, but also promote the development of hometown where achievement can be harvested by giving full play to personal ability, so that more young people are willing to return to hometown and devote themselves to the cause of agricultural development.

Government is supposed to increase economic support and policy support for farmers. According to the characteristics of agricultural development, government should reasonably adjust the investment direction of agricultural funds and the structure of capital investment so that financial input can play a better role and become a solid backing for the economic development of agriculture and agricultural products. To implement the effective agricultural subsidy policy, according to different situations of regional agricultural development, it is necessary to firstly understand the characteristics of local agriculture, and make the corresponding subsidy policy from the past simply raising the income of farmers to encourage them to develop independently, improve farmers' enthusiasm for planting, and enhance features and quality of products through the development of characteristic agriculture. Due to differences of regional natural environment, crops planted in different regions will present different states. By combining science and technology and advanced genetic technology of agricultural products, it is effective to increase economic benefits of high agricultural products by improving the quality, nutritive value and taste of crops which are suitable to plant in this area, so that the crops will become the characteristic agricultural products of this region. In addition, our country is also supposed to reduce the economic burden of farmers from tax policy, and further improve their vested interests of agricultural products in combination with various preferential policies.

The development of agriculture and the improvement of economic benefits of agricultural products are inseparable from supports of professional talents and scientific agricultural technology. There are a lot of agricultural universities in our country. It is feasible to encourage talents cultivated by these universities to train and develop in local and improve scientific and technological contents of agriculture in our country. In the field of encouraging professional personnel to engage in practical production research, it is vital to formulate corresponding subsidy policies to improve working enthusiasm of talents, and control the loss of talents by providing various safeguards for professional talents involved in production. By introducing talents, agricultural Scientific Outlook on Development can be effectively established, providing a strong impetus for the promotion of China's agricultural and agricultural products economy.

At present, agricultural economy in China is in a turning stage which is in need of timely optimization of industrial structure in order to better promote the rebirth of agricultural economy and stimulate the new vitality. Traditional agricultural economy still stays in the first industry stage, relying solely on the production of agricultural products to obtain economic benefits. It is obviously 
not flexible to obtain economic benefits through this way. In order to better develop agricultural economy and agricultural product economy, it is necessary to make use of economic principles to adjust the structure of agricultural industry, increase the proportion of second and third industries on the original basis, and promote the better improvement of economic benefits of agriculture. In particular, it is through scientific guidance to make our agriculture form a complete system from the planting, processing and sale of agricultural products, which is conducive to expanding the way to obtain economic benefits. In this regard, it is also needed to raise the brand awareness of agricultural producers and establish a sense of economic management so as to enable farmers to run factories or enterprises.

Plant protection technology is the key technology in green agricultural production in China, mainly through technical means which will not cause pollution or harm to the environment. In the production process of agricultural products, prevention and control of insects and pests is conducive to China's environmental protection and sustainable agricultural development. Plant protection technology can replace a large number of chemical pesticides and chemical fertilizers through physical means. It can effectively avoid the phenomenon that pesticides in some agricultural products have exceeded the standard and effectively improve the safety and quality of agricultural products in our country, thus increasing the competitiveness of agricultural products in our market or even in the international market, raising the economic income of agricultural products and improving its economic benefits. Through the establishment of the concept of green agricultural development of farmers, it is in favor of better ensuring the sustainable growth of our agricultural economy and playing an important role in ensuring the health of the people in our country.

\section{Conclusion}

The improvement of economic benefits of agriculture and agricultural products is the basis for ensuring the stability of our country and improving the country's self-reliance and self-reliance, as well as a guarantee for China's overall economic development. Therefore, it is necessary to improve the support for the development of agriculture and the improvement of economic benefits of agricultural products in both policy and economic aspects, realizing to meet normal needs of our country for agricultural products. Moreover, scientific development of agriculture can improve the quality of agricultural products, enable agricultural products of our country to occupy a more important position in the world market and let our agriculture to provide impetus for economic development.

\section{Acknowledgement}

The work was supported by the Youth Project of the 13th Five-Year Plan of Social Sciences in Jiangxi Province with the project number 17GL27 and the project name Research on the Strategy of Promoting the Market Competitiveness of Jiangxi Agricultural Products from the Perspective of Regional Brand Umbrella.

\section{References}

[1] Yin Chengjie. International Competitiveness of Agriculture and Measures to Improve the Competitive Power of Agriculture in China [J]. Issues in Agricultural Economy, 2003,01:5-10+79.

[2] Chen Yuanshuang. Measures to Improve China's Agriculture and Agricultural Products' Economic Efficiency [J]. China Market, 2008,23:56-57.

[3] Zhou Rongrong. Strategic Orientation of Agricultural Sustainable Development and Transition of Ecological Construction [D]. Nanjing Agricultural University, 2002.

[4] Yang Wanjiang. Study on Economic Benefits of Safe Agricultural Production [D]. Zhejiang University, 2006. 
[5] Zhang Xitao. Analysis of the Impact of Applying Geographical Indications on the Economic Benefits of Agricultural Products [D]. Nanjing Agricultural University, 2007.

[6] Zha Xuedong. Giving Full Play to Network Advantages is An Important Measure to Enhance the Economic Benefits of Agricultural Products [J]. Modern Agricultural Technology, 2007,19:222+225. 